University of Nebraska - Lincoln

DigitalCommons@University of Nebraska - Lincoln

November 1995

\title{
Magnetic switching volumes of CoSm thin films for high density longitudinal recording
}

\author{
E.W. Singleton \\ University of Nebraska - Lincoln \\ Z.S. Shan \\ University of Nebraska - Lincoln \\ Y.S. Jeong \\ University of Nebraska - Lincoln \\ David J. Sellmyer \\ University of Nebraska-Lincoln, dsellmyer@unl.edu
}

Follow this and additional works at: https://digitalcommons.unl.edu/physicssellmyer

Part of the Physics Commons

Singleton, E.W.; Shan, Z.S.; Jeong, Y.S.; and Sellmyer, David J., "Magnetic switching volumes of CoSm thin films for high density longitudinal recording" (1995). David Sellmyer Publications. 92.

https://digitalcommons.unl.edu/physicssellmyer/92

This Article is brought to you for free and open access by the Research Papers in Physics and Astronomy at DigitalCommons@University of Nebraska - Lincoln. It has been accepted for inclusion in David Sellmyer Publications by an authorized administrator of DigitalCommons@University of Nebraska - Lincoln. 


\title{
Magnetic Switching Volumes of CoSm Thin Films for High Density Longitudinal Recording
}

\author{
E.W. Singleton, Z.S. Shan, Y.S. Jeong and D.J. Sellmyer \\ Behlen Laboratory of Physics and Center for Materials Research and Analysis \\ University of Nebraska \\ Lincoln, Nebraska 68588-0111
}

\begin{abstract}
For a high density recording media, the magnetic switching volume is of great importance when considering media noise and thermal stability. CoSm//Cr films have been prepared and the influence of the $\mathrm{Cr}$ underlayer thickness and of the magnetic layer preparation conditions on the magnetic switching volume have been investigated through magnetic viscosity and remnance curve measurements. The measured switching volumes ranged from 3.0 to $15.2 \times 10^{-18} \mathrm{~cm}^{3}$, and implications regarding noise and thermal stability are discussed.
\end{abstract}

\section{INTRODUCTION}

CoSm thin films on $\mathrm{Cr}$ underlayers $(\mathrm{CoSm} / / \mathrm{Cr})$ have attracted recent attention as a potential material for high density longitudinal magnetic recording media [1]. These films have been fabricated with relatively high magnetic anisotropy and fairly large coercivity of the order 2-4 kOe [1]-[3]. Recent investigations of the nanostructure of the $\mathrm{Cr}$ underlayer of these films indicate there is a grain-like structure with a typical dimension of $25 \mathrm{~nm}$. For thin $\mathrm{CoSm}$ films $(\leq 30 \mathrm{~nm})$ deposited on a $\mathrm{Cr}$ underlayer, the $\mathrm{CoSm}$ layer replicated the structure of the underlayer. Atomic force microscopy (AFM) characterization reveals a $\mathrm{Cr}$ structure with a rice-like shape which is also inherited by the $\mathrm{CoSm}$ layer. Detailed transmission electron microscopy (TEM) studies of the $\mathrm{CoSm}$ grains show a structure consisting of $\mathrm{CoSm}$ nanocrystallites of a typical dimension of $5 \mathrm{~nm}$ embedded in an amorphous CoSm matrix [3], [4]. The volume fraction of the nanocrystallites is a function of argon pressure during film deposition and ranges from $\sim 50$ to $\sim 90 \%$ [3], [4]. The nanostructure affects the hard magnetic properties of the film.

By measuring the time dependence of magnetization and the irreversible susceptibility one may ascertain the magnetic switching volume of reversal within a magnetic material. The switching volume is an important consideration in that it influences the media noise and thermal stability in high density magnetic recording. The switching volume is likely affected by the film deposition conditions, including the underlayer thickness, magnetic layer thickness and sputtering pressure. Here we report the results of magnetic viscosity measurements on a series of films prepared with various sputtering conditions, namely varying the $\mathrm{Cr}$ underlayer thickness ( 0 to $120 \mathrm{~nm}$ ), CoSm film thickness ( 6 to 96 $\mathrm{nm}$ ) and argon sputtering pressure ( 5 to $30 \mathrm{~m}$ Torr). The magnetic switching volumes determined are discussed in relation to the magnetic properties and microstructure of the films and with regard to medium noise and thermal stability.

Manuscript received February 17, 1995. E.W. Singleton, e-mail ews@unlinfo.unl.edu; D.J. Sellmyer, e-mail cmra@unlinfo.unl.edu, fax 402-472. 2789. This work supported by ARPANSIC under Grant No. MDA972-93-10009 , and by the Center for Materials Research and Analysis, University of Nebraska.

\section{THEORETICAL CONSIDERATIONS}

A magnetic material that exhibits hysteresis effects also exhibits time dependence of magnetization [5], [6]. If a magnetic field is applied to a ferromagnet, its magnetization continues to vary with time once the change in magnetic field has stopped. Under appropriate conditions, normally near the coercive field, the change in magnetization often follows the relation [6]

$$
M(H, t)=M\left(H, t_{0}\right) \pm S(H) \ln (t),
$$

where $M$ is the net magnetization, $S$ the viscosity coefficient and $t$ the time elapsed since the last field change. The origin of the time dependence of magnetization is in thermally activated magnetization transitions over anisotropy energy barriers. The time dependence is related to the energy barrier distribution, a measure of which is the irreversible susceptibility, $\chi_{\text {irr }}$. The values of $S$ and $\chi_{\text {ir }}$ vary similarly as they are related by a fluctuation field used as a measure of thermal activation energy. The maximum values of $S$ and $\chi_{\text {irr }}$ reflect the behavior of the most numerous energy barriers and are generally found near the coercive field. In effect, this means that the coercivity characterizes the switching of the most typical magnetic grains in the sample. The switching volume $(V)$ can be shown to be related to the effective fluctuation field given by [7]

$$
H_{f}=\frac{S}{\chi_{i r r}}=\frac{k_{B} T}{V M_{s}} .
$$

The dimensions of the switching volume as defined here can be considered the length scale appropriate to the average magnetic grain involved in magnetization reversal.

\section{EXPERIMENT}

$\mathrm{CoSm} / / \mathrm{Cr}$ films were sputtered on glass substrates with a DC magnetron sputtering apparatus. The CoSm targets were made of pressed and sintered powder and the $99.9 \%$ purity $\mathrm{Cr}$ target was obtained commercially. Base sputtering pressure was $2 \times 10^{-7}$ Torr and sputtering pressures ranged from about 5 to 30 mTorr of argon gas. Sputtering rates for CoSm were about 0.1 $\mathrm{nm}$ per second and for $\mathrm{Cr}$ about 0.25 to $0.50 \mathrm{~nm}$ per second.

Samples were chosen for viscosity measurements with varying preparation conditions resulting in variations in the hard magnetic properties. One series of samples was prepared from a $\mathrm{Co}_{4.2} \mathrm{Sm}$ target (samples \#1-5). In these samples, the $\mathrm{Ar}$ pressure for both the $\mathrm{Cr}$ and CoSm layers changes from 5 to $30 \mathrm{mT}$ and the $\mathrm{Co}_{4.2} \mathrm{Sm}$ layer thickness varies from 6 to $96 \mathrm{~nm}$. The second series 
TABLE 1. Summary of sample preparation conditions, magnetic properties, maximum viscosity coefficient, maximum irreversible susceptibility and calculated switching volume.

\begin{tabular}{|c|c|c|c|c|c|c|c|c|c|}
\hline$\underset{\#}{\text { Sample }}$ & $\begin{array}{c}\mathrm{d}_{\mathrm{Cr}} \\
(\mathrm{nm})\end{array}$ & $\underset{\text { (mTorr) }}{\mathrm{P}_{A s}}$ & $\begin{array}{l}\mathrm{d}_{\mathrm{smco}} \\
(\mathrm{nm})\end{array}$ & $\underset{\text { (mTorr) }}{\mathbf{P}_{\mathrm{Ar}}}$ & $\begin{array}{c}\mathrm{H}_{\mathrm{c}} \\
(\mathrm{kOe})\end{array}$ & $\underset{\left(\mathrm{emu} / \mathrm{cm}^{3}\right)}{\mathrm{M}_{3}}$ & $\begin{array}{c}S_{\max } \\
\left(10^{-6} \mathrm{emu}\right)\end{array}$ & $\begin{array}{c}\chi_{\text {ir }} \\
\left(10^{-7} \mathrm{emu} / \mathrm{Oe}\right)\end{array}$ & $\begin{array}{c}\mathrm{V} \\
\left(10^{18} \mathrm{~cm}^{3}\right)\end{array}$ \\
\hline 1 & 120 & 5 & 24 & 5 & 0.73 & 700 & 8.2 & 17.4 & 12.6 \\
\hline 2 & 120 & 12 & 24 & 12 & 2.68 & 708 & 15.9 & 14.5 & 5.3 \\
\hline 3 & 120 & 30 & 24 & 30 & 0.86 & 808 & 5.5 & 10.5 & 9.8 \\
\hline 4 & 120 & 12 & 6 & 12 & 1.38 & 670 & 2.7 & 1.3 & 3.0 \\
\hline 5 & 120 & 12 & 96 & 12 & 1.14 & 810 & 18.5 & 55.0 & 15.2 \\
\hline 6 & 0 & 7 & 30 & 25 & 1.6 & 350 & 6.3 & 6.5 & 12.2 \\
\hline 7 & 20 & 7 & 30 & 25 & 2.32 & 350 & 4.2 & 2.6 & 7.3 \\
\hline 8 & 39 & 7 & 30 & 25 & 2.8 & 350 & 5.4 & 2.8 & 61 \\
\hline 9 & 53 & 7 & 30 & 25 & 3.12 & 350 & 6.0 & 3.1 & 6.1 \\
\hline 10 & 79 & 7 & 30 & 25 & 3.1 & 350 & 5.8 & 3.1 & 6.3 \\
\hline
\end{tabular}

of samples was prepared from a $\mathrm{Co}_{3.7} \mathrm{Sm}$ target (samples \#6-10). In these samples, the CoSm layer was held at a constant thickness of $30 \mathrm{~nm}$ and the $\mathrm{Cr}$ underlayer was varied from 0 to $79 \mathrm{~nm}$. The magnetic properties were measured with a commercial alternating gradient force magnetometer (MicroMag ${ }^{\mathrm{TM}} 2900$ ).

During magnetic viscosity measurements, the films were oriented with the film plane parallel to the applied field (along the easy direction), and saturated with a $10 \mathrm{kOe}$ field. A reverse field near the coercive field was then applied and the magnetization monitored over a time span up to 1500 seconds. The curves $\chi_{\text {in }}(\mathrm{H})$ were derived from d.c. demagnetization remnance curves.

\section{RESULTS AND DISCUSSION}

Viscosity measurements reveal a ln time dependence of magnetization for all samples in the range of fields and times studied. By fitting viscosity data to equation 1 , the coefficient $S$ was determined. Figure 1 shows the variation of the irreversible susceptibility and the viscosity coefficient for a range of fields near the coercive field for a $\mathrm{CoSm} / \mathrm{Cr}$ film (sample \#2). The $\mathrm{S}$ and $\chi_{\text {irr }}$ peak at fields very near $\mathrm{H}_{\mathrm{c}}$. From the maximum values of the $\mathrm{S}$ and $\chi_{\text {irr }}$ found for each sample, the switching volumes were calculated. Table I summarizes preparation conditions, magnetic properties and the calculated switching volume (V) of each sample.

The switching volume is found to increase with the CoSm layer thickness ( 6 to $96 \mathrm{~nm}$ ) from 3.0 to $15.2 \times 10^{-18} \mathrm{~cm}^{3}$ when deposited at $12 \mathrm{mT} \mathrm{Ar}$ (samples \#4, 2 and 5). For samples deposited at varied sputtering pressure ( 5 to $30 \mathrm{mT}$ ) and constant CoSm layer thickness $(24 \mathrm{~nm})$, a smaller variation of switching volume is seen (samples \#1,2 and 3). Figure 2. shows the effect of varying the $\mathrm{Cr}$ underlayer thickness ( 0 to $79 \mathrm{~nm}$ ) while maintaining a constant CoSm layer thickness $(30 \mathrm{~nm})$, on the switching volume and sample coercivity (samples \#5-10). The switching volume decreases quickly with increasing $\mathrm{Cr}$ layer thickness and remains nearly constant up to relatively large underlayer thickness. The observed decrease in $\mathrm{V}$ with increasing $\mathrm{Cr}$ layer thickness supports the observed improvement in the carrier-to-total integrated noise ratios (CINR) vs. linear recording density on similar CoSm disks prepared with and without a $\mathrm{Cr}$ underlayer by E.M.T. Velu et.al. [2]. The $\mathrm{Cr}$ underlayer isolates the CoSm grains for relatively thin $\mathrm{CoSm}$ layers resulting in smaller switching volumes (and correspondingly lower noise). The absence of a $\mathrm{Cr}$ underlayer allows for larger magnetic interactions and an increased switching volume (and an increase in noise). For relatively thick CoSm layer (sample \#5), the switching volume is somewhat larger than in the thinner (CoSm layer $=24 \mathrm{~nm}$ ) samples (An exception exists for sample \#1 which will be discussed later). AFM shows the $96 \mathrm{~nm}$ thick CoSm layer in sample \#5 fills in much of the space or voids between the rice-like grains [3], [8] resulting in an increased switching volume. This is possibly the cause of the larger CINR vs density seen in disks tested with thick CoSm layers compared to a thinner CoSm layer [2]. In sample \#1, a relatively large switching volume is seen in comparison to the other samples with a $24 \mathrm{~nm} \operatorname{CoSm}$ layer. This may be a result of the large volume fraction of CoSm crystallites ( $90 \%)$ found in the magnetic layer of these films [3], [4]. In addition, the lower $5 \mathrm{mT}$ sputtering pressure results in a smoother surface morphology. The combination of these factors

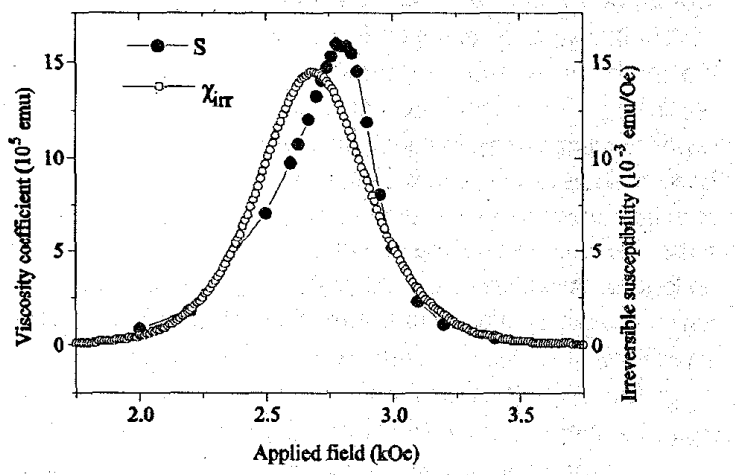

Figure 1. Variation of viscosity coefficient (S) and irreversible susceptibility $\left(\chi_{\text {in }}\right)$ as a function of reverse field for $\mathrm{CoSm} / / \mathrm{Cr}$ film (sample \#2) at room temperature. 


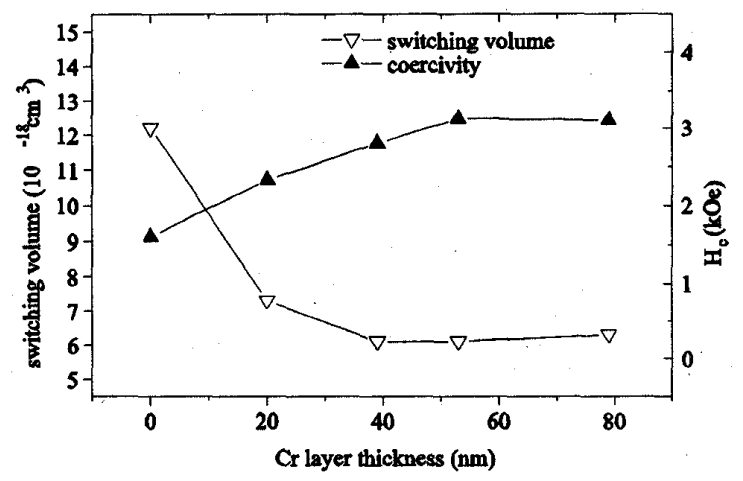

Figure 2. Variation of switching volume as a function of $\mathrm{Cr}$ underlayer thickness (samples \#5-10).

may lead to enhanced intergranular coupling and the larger observed switching volume.

Using the calculated magnetic switching volumes and the film thickness of the CoSm layer, the diameter of the magnetic grain can be estimated assuming it is a cylindrical cell whose height is the thickness of the CoSm film. The diameters are in the range of 14 to $26 \mathrm{~nm}$ which are generally similar to the average size of the $\mathrm{Cr}$ underlayer as determined by TEM [3], [4]. Thus, reversal of magnetization occurs in switching units of dimensions of the $\mathrm{Cr}$ grains rather than the small $5 \mathrm{~nm}$ CoSm crystallites.

For high density magnetic recording, a rather high anisotropy material with oriented and exchange-decoupled grains is necessary so that there is low noise. The high $\mathrm{K}_{u}$ value is needed so the thermal stability limit is not approached in the very small grains. The thermal stability requirement is that $\mathrm{K}_{\mathrm{u}} \mathrm{V} / \mathrm{k}_{\mathrm{B}} \mathrm{T} \geq \sim 100$, where $\mathrm{K}_{u}, \mathrm{~V}, \mathrm{k}_{\mathrm{B}}$ and $\mathrm{T}$ are the uniaxial anisotropy constant, grain

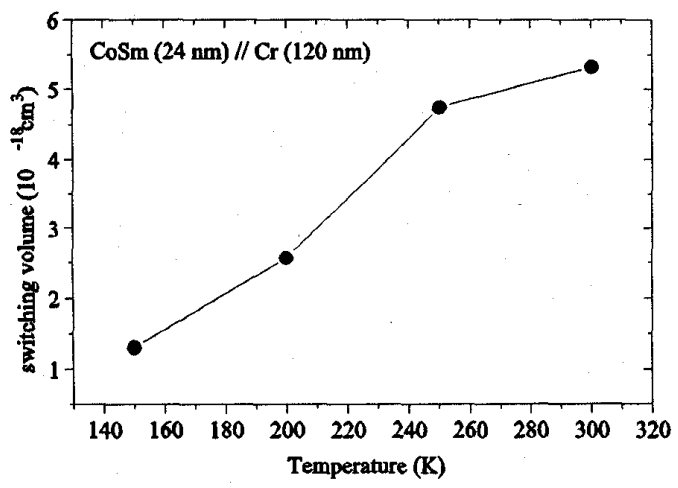

Figure 3. Temperature dependence of switching volume for sample \#2. volume, Boltzman constant and temperature, respectively [9],[10]. For noise considerations small grains are necessary and it has been shown that $\mathrm{K}_{\mathrm{u}} \mathrm{V} \sim 6.6 \times 10^{-12}$ erg may be necessary in order to achieve acceptable signal to noise ratio in the media [10]. Thus an obvious trade-off of benefits with respect to magnetic switching volume exists.

If one considers the switching volumes of the size determined in this study along with the uniaxial anisotropy constant determined by measuring magnetization curves parallel and perpendicular to the film plane $\left(\mathrm{K}_{\mathrm{u}} \sim 5 \times 10^{6} \mathrm{erg} / \mathrm{cm}^{3}\right)$, the magnetic switching unit may be sufficiently large to exceed the thermal stability requirement. However, the switching volume may be too large for noise considerations.

Low temperature viscosity and irreversible susceptibility measurements of sample \#2 reveal an increase in switching volume with increasing temperature (Fig. 3). This behavior may be indicative of magnetization reversal by domain wall pinning or domain wall nucleation and propagation, whereas a constant switching volume with temperature would indicate reversal by coherent rotation [11]. Further magnetic measurements support a pinning reversal mechanism and will be reported in detail in a paper in preparation.

\section{REFERENCES}

[1] E.M.T. Velu and D.N. Lambeth, "CoSm-based high-coercivity thin films for longitudinal recording," J. Appl. Phys., vol. 69, pp. 5175$5177,1991$.

[2] . E.M.T. Velu and D.N. Lambeth, "High density recording on $\mathrm{SmCo} / \mathrm{Cr}$ thin film media," IEEE Trans. Magn., vol. 28, pp. 3249-3254, 1992.

[3] D.J. Sellmyer, Z.S. Shan, Y. Liu, S.H. Liou, S.S. Malhotra and B.W. Robertson, "Magnetic and structural properties of high coercivity nanocrystalline CoSm films with in-plane anisotropy," Acta. Met. and Mater., (in press).

[4] Y. Liu, B.W. Robertson, Z.S. Shan, S. Malhotra, M.J. Yu, S.K. Renukunta, S.H. Liou and D.J. Sellmyer, "Nanostructures of Sm-Co on Cr thin films," IEEE Trans. Magn., vol. 30, pp. 4035-4037, 1994.

[5] L: Néel, "Théorie du Trainage Magnétique des Substances Massives dans le Domaine de Raleigh," J. de Phys. de Radium, vol. 11, pp. 49. 61, 19.50 .

[6] R. Street and J.C. Woolley, "A study of magnetic viscosity," Proc. Phys. Soc. Sect. A, vol. 62, pp. 562-572, 1949.

[7] E.P. Wohlfarth, "The coefficient of magnetic viscosity," J. Phys. F: Met. Phys., vol. 14, pp. L155-159, 1984.

[8] E.M.T. Velu, D.N. Lambeth, J.T. Thorton and P.E. Russel, "AFM structure and media noise of $\mathrm{SmCo} / \mathrm{Cr}$ thin films and hard disks," $J$. Appl. Phys., vol. 75, pp. 6132-6134, 1994.

[9] M.P. Sharrock, "Time dependence of switching fields in magnetic recording media," J. Appl. Phys., vol 76, pp. 6413-6418, 1994.

[10] M.P. Sharrock, "Time-dependent magnetic phenomena and particlesize effects in recording media," IEEE Tran. Magn., vol 26, pp. 193$197,1990$.

[11] D. Givord, Q. Lu, M.R. Rossignol, P. Tenaud and T. Viadieu, "Experimental approach to coercivity analysis in hard magnetic materials," J. of Magn. Magn. Mater., vol 38, pp. 183-188, 1990. 